\title{
Can Single Incision Laparoscopic Surgery be Considered Primarily for Patients with Complicated Appendicitis?
}

\author{
Seon Hahn Kim, Jung Myun Kwak \\ Department of Surgery, Korea University College of Medicine, Seoul, Korea
}

See Article on Page 388-394

The growing enthusiasm to develop more minimally invasive surgical techniques has led laparoscopic surgeons to try to reduce the number of skin incisions or to even avoid them. Natural orifice transluminal endoscopic surgery (NOTES) and single incision laparoscopic surgery (SILS) have been proposed as emerging experimental alternatives to conventional surgery [1]. In spite of the potential benefits of NOTES over laparoscopic techniques, widespread clinical implementation of NOTES is still a long way off. Several limiting factors, such as an unfamiliar visual approach, limitations of existing instruments, and the lack of a stable surgical platform, have not yet been conquered. Moreover, the resulting viscerotomy and its closure remain challenges to established surgical and ethical principles [2].

While NOTES has struggled with these limitations, SILS is becoming increasingly popular among surgeons and is expanding its applications. Numerous studies have shown that SILS is feasible for a wide variety of surgical procedures in the fields of general surgery, urology and gynecology [3]. The appendectomy is one of the most frequent operations in SILS. Although the opinion that a SILS appendectomy can be considered primarily for cases of uncomplicated diseases is dominant and it is technically more challenging to apply SILS for patients with complicated appendicitis, it is being attempted with increasing frequency [4-6]. Clearly, SILS will continue to evolve and expand its indications while keeping pace with the development of instruments and techniques, at least for the time being. The development of robot-assisted SILS may help to overcome many

Correspondence to: Seon Hahn Kim, M.D.

Colorectal Division, Department of Surgery, Korea University Anam Hospital, Korea University College of Medicine, 126-1 Anam-dong 5-ga,

Sungbook-gu, Seoul 136-705, Korea

Tel: +82-2-920-6644, Fax: +82-2-928-1631

Email:drkimsh@korea.ac.kr

(C) 2010 The Korean Society of Coloproctology

This is an open-access article distributed under the terms of the Creative Commons Attribution NonCommercial License (http://creativecommons.org/licenses/by-nc/3.0) which permits unrestricted noncommercial use, distribution, and reproduction in any medium, provided the original work is properly cited. of the technical difficulties [7]. Attention is now focusing on how far it will develop and on how much its area of application will widen.

Considering the refinement of indications for SILS, this study may be valuable because the authors focused on the feasibility and the benefits of SILS for "complicated" appendicitis. They reported better cosmetic result and similar postoperative complication rates of SILS for complicated appendicitis than of a conventional laparoscopic appendectomy. As far as we are currently aware, the main benefit to the patients undergoing SILS is superior cosmesis, but the questions remain as to whether a smaller or lesser incision correlates to a better clinical outcome. Unfortunately, this study obviously suffers from being a retrospective study. The sample size in each group is small, making it difficult to ascertain the differences in clinical parameters between the groups. To answer the question of whether the SILS appendectomy is technically feasible and safe in patients with complicated appendicitis, a larger number of patients is needed. Additional trocars were placed in 40 percent of the cases in this study, higher than in other reports $[3,6]$. Since the expected benefit compared with conventional laparoscopy is likely to be small, a low threshold for using an additional port or for converting to conventional laparoscopic surgery may be essential. Multicenter, prospective, randomized trials are necessary to verify the safety, efficacy and feasibility of SILS for complicated appendicitis.

\section{REFERENCES}

1. Chukwumah C, Zorron R, Marks JM, Ponsky JL. Current status of natural orifice translumenal endoscopic surgery (NOTES). Curr Probl Surg 2010;47:630-68.

2. Yan SL, Thompson-Fawcett M. NOTES: new dimension of minimally invasive surgery. ANZ J Surg 2009;79:337-43.

3. Ahmed K, Wang TT, Patel VM, Nagpal K, Clark J, Ali M, et al. The role of single-incision laparoscopic surgery in abdominal and pelvic surgery: a systematic review. Surg Endosc. 2010 Jul 10 [Epub]. DOI: 10.1007/s00464-010-1208-6.

4. Kim HJ, Lee JI, Lee YS, Lee IK, Park JH, Lee SK, et al. Single-port transumbilical laparoscopic appendectomy: 43 consecutive cases. 
Surg Endosc 2010;24:2765-9.

5. Cho MS, Min BS, Hong YK, Lee WJ. Single-site versus conventional laparoscopic appendectomy: comparison of short-term operative outcomes. Surg Endosc. 2010 Jun 5 [Epub]. DOI: 10.1007/ s00464-010-1124-9.

6. Muensterer OJ, Puga Nougues C, Adibe OO, Amin SR, George- son KE, Harmon CM. Appendectomy using single-incision pediatric endosurgery for acute and perforated appendicitis. Surg Endosc 2010;24:3201-4.

7. Ostrowitz MB, Eschete D, Zemon H, DeNoto G. Robotic-assisted single-incision right colectomy: early experience. Int J Med Robot 2009;5:465-70. 